gen" kommen. Besonders wertvoll scheinen dem Ref. die vielen Skizzen und Photographien nach Originalen, die es wohl verdienten, im Chemie-Unterricht. vorgeführt $\mathrm{zu}$ werden. Es ist ein reiner Genuß für wissenschaftsgeschichtlich interessierte Chemiker, dieses Büchlein in einem Zug zu lesen. Es erübrigt. sich, ein eingehend begründetes Werturteil zu fällen; allein der Name des. Autors bürgt ja für eine mustergültige chemiegeschichtliche Studie.

\title{
J. Gicklhorn-Wien.
}

Hans Vogel: Chemie und Technik der Vitamine. 3. Aufl. 1. Band. Die fettlöslichen Vitamine. Bearbeitet von Doz. Dr. H. Knobloch. Mit 25 Abb. und 52 Tab. VII, 485 S. Stuttgart: F. Enke. 1950. DM 45,60, geb. DM 48,60 .

Das Tempo der Fortschritte ist besonders auf bestimmten Gebieten beängstigend. $\mathrm{Zu}$ diesen gehören die Vitamine, deren Bedeutung für die Biologie und Medizin eino treibende Kraft für die chemische Bearbeitung ist. Die 3. Aufl. des vorliegenden Buches mußte in zwei Bände geteilt werden. Der erste behandelt die fettlöslichen Vitamine A (133 S.), D (80 S.), E (60 S.), K (48 S.), die essentiellen Fettsäuren (15 S.) und den „Antistiffness“"Faktor.

In den einzelnen Kapiteln ist die Stoffeinteilung ungefähr in folgender Art getroffen: Nach der Beschreibung der Chemie des betreffenden Vitamins wird auf die Zusammenhänge der Wirkung mit der chemischen Konstitution eingegangen. Dann folgt die Darstellung der Vitamine und eventuell der Provitamine, wobei auch auf die technischen Verfahren eingegangen wird. Dem Nachweis und den Bestimmungsmethoden folgen Angaben über die Maßeinheiten, die Biologie und den Wirkungsmechanismus. Am Ende jedes Kapitels ist die Literatur in großer Vollständigkeit (alphabetische Reihenfolge der Autoren) etwa bis Ende 1949 zusammengefaßt. Um einen Anhaltspunkt über das Ausmaß der verarbeiteten Literatur zu geben - darin liegt ja der Hauptwert des Buches, da es jedem auf dem Gebiete der Vitamine Arbeitenden ein unerläßlicher Führer sein will - sei die Anzahl der bei den einzelnen Vitaminen angegebenen Literaturstellen verzeichnet: Vitamin A: 797, Vitamin D: 547, Vitamin E: 396, Vitamin K: 372, Fettsäuren: 137.

Ein für den Chemiker sehr wichtiger Abschnitt ist das Verzeichnis aller Patente über fettlösliche Vitamine, soweit sie in den wichtigsten Referierorganen bis Ende 1949, manchmal auch bis März 1950, enthalten sind. Ein 9 Seiten umfassendes Sachverzeichnis schließt den Band ab.

Der Autor hat eine große Leistung vollbracht und sich den Dank jedes mit Vitaminen arbeitenden Chemikers verdient, in dessen Bibliothek das Buch nicht fehlen darf. F. Wessely.Wien.

\section{Berichtigung.}

Im Beitrag „Polarographische Bestimmung von k-Strophantin" von F. X. Mayer, H. Jansch und G. Machata (diese Zeitschrift Bd. XXXVIII, H. 1 bis 2, S. 59, 1951) muß es heißen:

S. 62 , 2. Zeile von oben: „46 bis $50 \%$ “ statt „quantitativ“; S. 62, Zusammenfassung, 3. Zeile von oben: ,-2,18 $\mathrm{V}^{\prime}$ statt ,-2,3 $\mathrm{V}^{*}$. 